\title{
A Survey: IEEE 802.16 Wireless MAN (Wi-Max) using Various Modulation Techniques
}

\author{
Smriti Shrivastava, Md. Abdullah \\ Department of Electronics and Communication Engineering \\ Sagar Institute of Science and Technology, Bhopal, M.P., India
}

\begin{abstract}
The Wi-MAX (Worldwide Interoperability for Microwaves Access) is a efficient technology which can deliver videos, images and voice at higher datarates. The development of 802.16 standards for BWA (Broadband Wireless Access) technologies was encouraged by the rapidly growing need for higher datarates, everywhere and cost effective access. The Wi-MAX can also be considered to be the main technology in the implementation of other networks like wireless sensor networks. Developing an understanding of the Wi-MAX system can be best achieved by looking at a model of the WiMAX system. In this paper we are investigating the performance of IEEE 802.16 Wireless MAN network with various modulation techniques as well as other methodologies which inherently improve the performance of Wi-MAX System. Different methodologies have been proposed to enhance the performance of wireless communication system.
\end{abstract}

\section{Keywords}

IEEE 802.16, Digital Modulation Techniques, Linear and Non-Linear Algorithms.

\section{INTRODUCTION}

Orthogonal Frequency Division Multiplexing (OFDM) is an wireless modulation technology instead of CDMA. OFDM has the advantages to beat the capacity of CDMA systems and provide the wireless access method for 4th generation systems. OFDM is a multiplexing technique that allows digital data to be efficiently and reliably transmitted over a radio channel, also in carriers. These carriers are regularly spaced in frequency, preparing a bunch of frequencies. The frequency time and difference organization of the carriers is selected in such a means that the carriers are orthogonal, sense so as to they don't cause interference to one another. This is in spite of the frequency and these carriers are orthogonal to each other, i.e. OFDM. In OFDM, usable frequency band is divided into a large number of smaller frequency bands that are mathematically orthogonal using fast Fourier transforms (FFTs). Reconstruction of the band is performed by the inverse fast Fourier transform (IFFT). Carriers overlapping each other in the frequency domain. The name "OFDM" is derived from the fact that the digital data is sent using several carriers, each of a diverse reduction is drop in signal power when transmitting from one point to another which is caused due to shadowing /slow fading and it can be avoided by splitting the signal into several small frequency band carriers like OFDM does. This guide to small loss in carrier rather than complete loss. Delay spread is the time spread between the arrival of the first and last multipath signal detected by receiver. In modern communication system the delay spread can lead to ISI. This can be reduced in several ways, one method is to decrease the symbol rate by reducing the data rate for every channel which split the frequency band into additional channels with FDM another is to use a coding technique while is appropriate to ISI such as CDMA. In this paper we mostly focus on Wi-MAX technology. Most users are keen to use wireless medium with greater speed and that is supported using the existing infrastructure. Several researchers have been proved that WI-MAX is answer for user's expectation and this paper will answer to all the questions regarding confusion on choosing the best modulation technique to use to not only get better utilization of available frequency band but also how to minimize the BER. More information regarding WI-MAX specification and advantages is explained in [1]. WI-MAX at base level make use of OFDM and our research started with convenient model of OFDM and uses that model in WI-MAX to get better result.

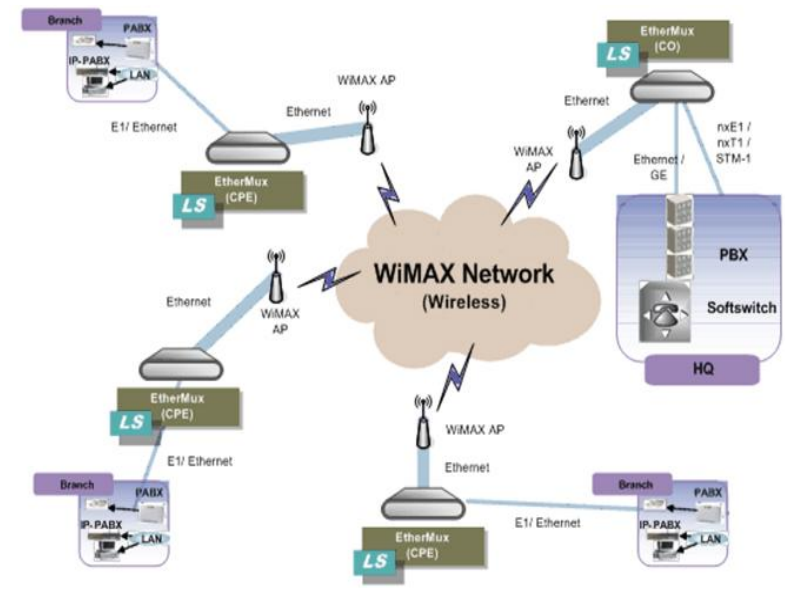

Figure 1.1 Wireless MAN Network[1]

\section{WI-MAX OFDM SYSTEM}

For better utilization of available frequency band but also how to minimize the BER. More information regarding WI-MAX specification and advantages is explained in [1]. WI-MAX at base level make use of OFDM and our research started with convenient model of OFDM and uses that model in WI-MAX to get improved results.

\section{The Physical Layer Description of Wi-MAX}

The IEEE 802.16 standard was firstly designed to address communications with direct visibility in the frequency band from $10 \mathrm{GHz}$ to $66 \mathrm{GHz}$. Because of the fact that non-line-ofsight(NLOS) transmissions are difficult when communicating at higher frequencies, the modification 802.16a was given for working in a lower frequency band, range $2 \mathrm{GHz}-11 \mathrm{GHz}$. The IEEE $802.16 \mathrm{~d}$ standard is a variation of the fixed standard (IEEE 802.16a) with the main advantage of optimizing the power utilization of the portable devices. The previous revision of this design is well recognized as IEEE 802.162004 [1].

Wi-MAX standard based products are considered to work not only with IEEE 802.162004 but also with the IEEE $802.16 \mathrm{e}$ standard. While the 802.162004 is introductorily intended for stationary communication, the $802.16 \mathrm{e}$ is oriented to both fix and portable applications. 


\section{PHY Layer Overview}

Wi-MAX is not truly new; rather, it is distinguished because it was designed from the position up to distribute max throughput to maximum distance even as offer $99.9 \%$ percent reliability. To achieve this, the designers (IEEE 802.16 Working Group D) relied on proven technologies for the PHY including orthogonal frequency division multiplexing (OFDM), time division duplex (TDD), frequency division duplex (FDD), Quadrature Phase Shift Keying (QPSK), and Quadrature Amplitude Modulation (QAM), to name only a few. Wi-MAX has a scalable physical-layer architecture that allows for the data rate to scale easily with available channel frequency range. This measurement is good for the O-FDMA approach, where the FFT (fast Fourier transform) points might be scaled based on the accessible channel frequency band. Such as, a Wi-MAX system may prefer 128,512 , or 1024 points FFTs based on either the channel frequency band is $1.25,5$, or $10 \mathrm{MHz}$ respectively. These modifications may be done dynamically to support user roaming across different networks that may have different frequency band allocations.

\section{OFDM Parameters in Wi-MAX}

As mentioned previously, the fixed and mobile versions of Wi-MAX have slightly different implementations of the OFDM physical layer. Fixed Wi-MAX, which belong to IEEE 802.16 2004, uses a 256 point FFT based OFDM physical layer. Mobile Wi-MAX, which is based on the IEEE 802.16e 2005 standard, uses a scalable OFDMA-based physical layer. In the case of mobile Wi-MAX, the FFT sizes can vary from 128 bits to 2048 bits.

Table I shows the parameters related to OFDM for both the OFDM PHY and the OFDMA PHY. The some parameters were shown for only a limited set of profiles that are probably to be deployed and don't include a thorough set of possible values.

Table I Parameters of Wi-MAX

\begin{tabular}{|l|c|c|c|c|c|c|}
\hline \multicolumn{1}{|c|}{ Parameter } & \multicolumn{1}{|c|}{$\begin{array}{c}\text { Fixed } \\
\text { WiMAX } \\
\text { OFDM }\end{array}$} & \multicolumn{5}{|c|}{$\begin{array}{c}\text { Mobile WIMAX } \\
\text { Scalable } \\
\text { OFDMA }\end{array}$} \\
\hline FFT size & 256 & 128 & 512 & 1024 & 2048 \\
\hline Number of used data suhcarriers & 192 & 72 & 360 & 720 & 1440 \\
\hline Number of pilot suhcalTiers & 8 & 12 & 60 & 120 & 240 \\
\hline $\begin{array}{l}\text { Number of null/guardhand } \\
\text { suhcarriers }\end{array}$ & 56 & 44 & 92 & 184 & 360 \\
\hline Cyclic prefix or guard time & & $1 / 4,1 / 8.1$ '16, 1/32 \\
\hline Channel bandwidth MHz) & 3.5 & 1.25 & 5 & 10 & 20 \\
\hline $\begin{array}{l}\text { Subcanier frequency spacing } \\
\text { (klIz) }\end{array}$ & 15.625 & \multicolumn{5}{|c|}{10.94} \\
\hline Useful symbol time (jis) & 64 & \multicolumn{5}{|c|}{91.4} \\
\hline Guard time assumin2 12.5\% (is) & 8 & \multicolumn{5}{|c|}{11.4} \\
\hline OFDM symbol duration (1us) & 72 & \multicolumn{5}{|c|}{402.9} \\
\hline $\begin{array}{l}\text { Number of OFDM symbols in 5 } \\
\text { ms frame }\end{array}$ & 69 & \multicolumn{5}{|c|}{} \\
\hline
\end{tabular}

\section{Wi-MAX OFDM-PHY}

In Mobile Wi-MAX, the FFT point is variable from 128 points to 2048 points. Here, when the available frequency band increases, the FFT points are also increased such that the sub carrier difference is must be $10.94 \mathrm{kHz}$. This utilize the symbol duration of OFDM, which is the essential supply unit, permanent and so makes scaling have least impact on higher layers. A variable design also keeps the costs cheap. The subcarrier difference of $10.94 \mathrm{kHz}$ was chosen as a good balance between satisfying the delay spread and Doppler spread requirements for operating in mixed fixed and mobile environments. This subcarrier difference can support delay- spread values up to $20 \mu \mathrm{s}$ and vehicular mobility up to 125 $\mathrm{km} / \mathrm{h}$ when operating in $3.5 \mathrm{GHz}$. A subcarrier difference of $10.94 \mathrm{kHz}$ implies that $128,512,1024$, and 2048 FFT are used when the channel frequency band is $1.25 \mathrm{MHz}, 5 \mathrm{MHz}$, $10 \mathrm{MHz}$, and $20 \mathrm{MHz}$, respectively. It must, be noted that mobile Wi-MAX might also include extra frequency band profiles.

Since increase the link throughput systems is the main goal of this work. Figure 1 depicts the block technique of a typical structure of a system with OFDM enabled Wi-MAX used in this paper. The Block diagram represents the whole system model or the signal chain at base band. The block system is divided into 2 main sections namely the transmitter and the receiver. On the other hand, the IEEE 802.16e standard is a revision to the 802.16-2004 base specification with the aim of targeting the mobile market by adding portability.

\section{DIGITAL MODULATION TECHNIQUES}

Most communications systems fall into one of three categories: frequency band efficient, power efficient, or cost efficient. Frequency band efficiency describes the ability of a modulation technique to accommodate data within a limited frequency band. Power efficiency describes the ability of the system to reliably send information at the lowest useful power level. In general systems, there is an urgent on frequency band efficiency. The parameter to be optimized depends on the demands of the exact system, the same as seen in the subsequent two examples. For creators of digital terrestrial microwave radios, their main concern is good frequency band effectiveness with low error rate. They have sufficient of power on hand and are not worried with power competence. They are not particularly anxious with receiver cost or difficulty because they do not have to build big numbers of them.

Alternatively, creators of hand-held cellular phones put a high priority on power efficiency because these phones require running on a battery. Price is too a main concern because cellular phones must be inexpensive to encourage new users. Accordingly, these systems sacrifice some frequency band efficiency to get power and lower cost. All the time one of these competence parameters are increased, another one decreases, becomes more complex, or does not perform well in an unfortunate environment. Cost is a leading system priority. Cheaper radios will forever be in requiring. In the premature era, it was possible to make a radio low-cost by sacrificing power and frequency band efficiency. This is no longer possible. The radio spectrum is very valuable and operators who do not use the spectrum efficiently could lose their existing licenses or lose out in the competition for new technologies. These are the tradeoffs that must be considered in digital RF communications design.
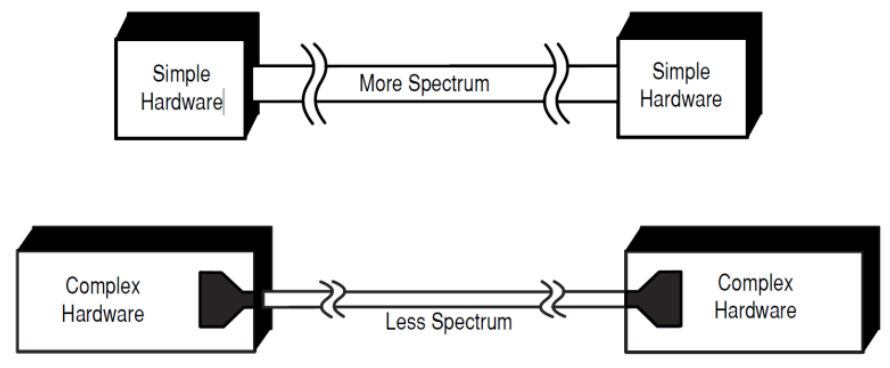

Figure 3.1 The Fundamental Trade-off [2] 


\subsection{Trading off simplicity and frequency band}

There is a fundamental tradeoff in communication systems. Simple hardware can be used in transmitters and receivers to correspond information. However, this uses a lot of spectrum which limits the numerous users. Alternatively, extra complex transmitters and receivers can be used to broadcast the same information over reduced frequency band. The change to increasing spectrally efficient transmission techniques requires growingly complex hardware. Complex hardware is hard to design, test, and construct. This tradeoff exists whether communication is through air or wire and analog or digital.

\subsection{Industry trends}

Over the past few years a most important transition has occurred from easy analog Amplitude Modulation and Frequency/Phase Modulation to new digital modulation schemes. Examples of digital modulation include

- Quadrature Phase Shift Keying

- $\quad$ Frequency Shift Keying

- $\quad$ Minimum Shift Keying

- Quadrature Amplitude Modulation

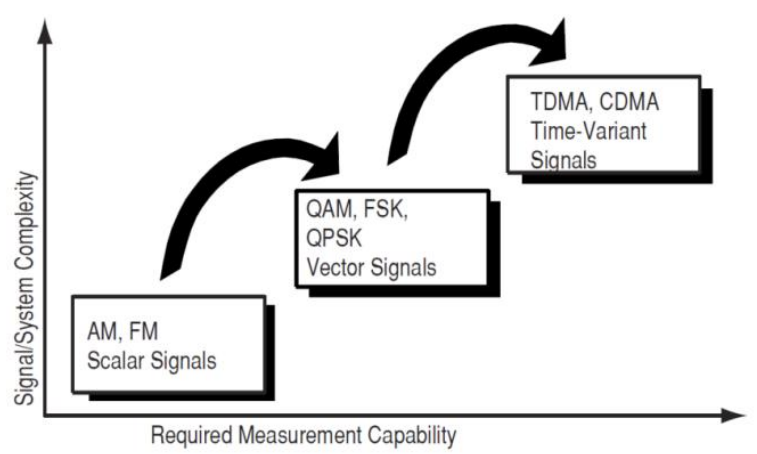

Figure 3.2 Trends in the Industry [2]

A new layer of difficulty in several new systems is multiplexing. Two major types of multiplexing are Time Division Multiple Access and Code Division Multiple Access. These are two unlike ways to add variety to signals allowing unlike signals to be separated from one another.
Amplitude

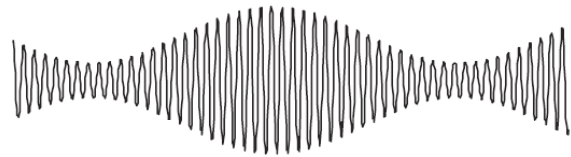

Frequency

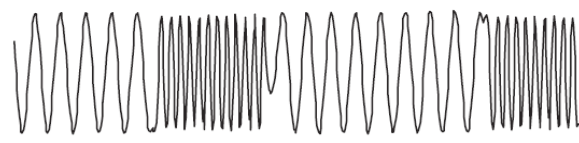

or

Phase

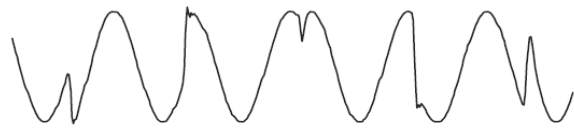

Both Amplitude

and Phase

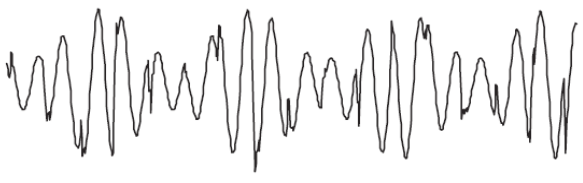

Figure 3.3 Signal Characteristics to modify[2]

In Amplitude Modulation, the amplitude of a high-frequency carrier signal is mixed in proportion to the immediate amplitude of the modulating information. Frequency Modulation is the most accepted analog modulation technique used in mobile communications systems. In Frequency Modulation, the amplitude of the modulating carrier is set constant whereas its frequency is mixed by the modulating message signal. Amplitude and phase can be modulated simultaneously and independently, but this is hard to generate, and particularly difficult to sense. In its place, in sensible systems the signal is split into another set of free components: I -In phase and Q -Quadrature. These mechanism are orthogonal and do not obstruct with each other.

\subsection{I and $Q$ in a radio transmitter}

$I / Q$ diagrams are mainly useful because they copy the way the majority digital communications signals are produced using an $I$ and $Q$ modulator. Inside transmitter, $I$ and $Q$ signals are mixed with the similar local oscillator (LO). A $90^{\circ}$ phase shifter is located in one of the LO paths. Signals that are split by $90^{\circ}$ are also identified as being orthogonal to one another or in Quadrature. Signals that are in Quadrature don't interfere with one another. They are two independent working of the signal. When recombined, they are summed to a merged output signal. Here two independent signals are in $I$ and $Q$ that can be sent and received with easy circuits. This simplifies the design of digital radios. The key advantage of $I / Q$ modulation is the simplicity of combining free signal components into a single composite signal and later splitting such a composite signal into its free component parts. 


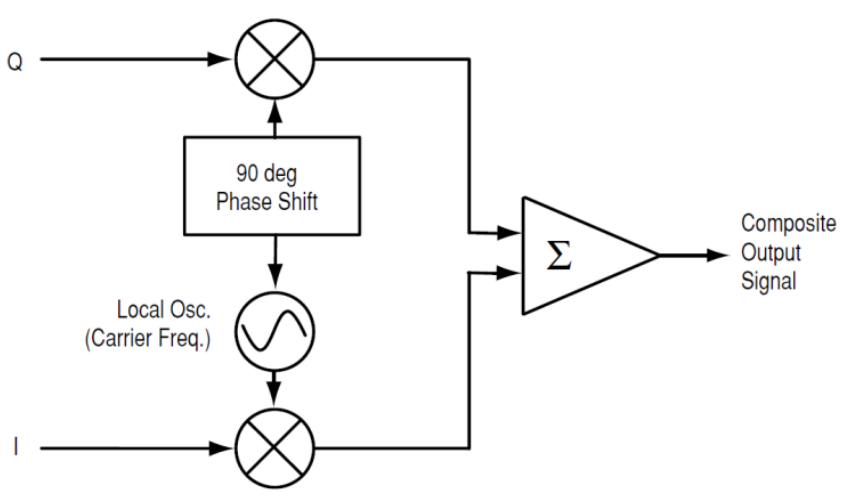

Figure 3.4 $I$ and $Q$ in a Practical Radio Transmitter [2]

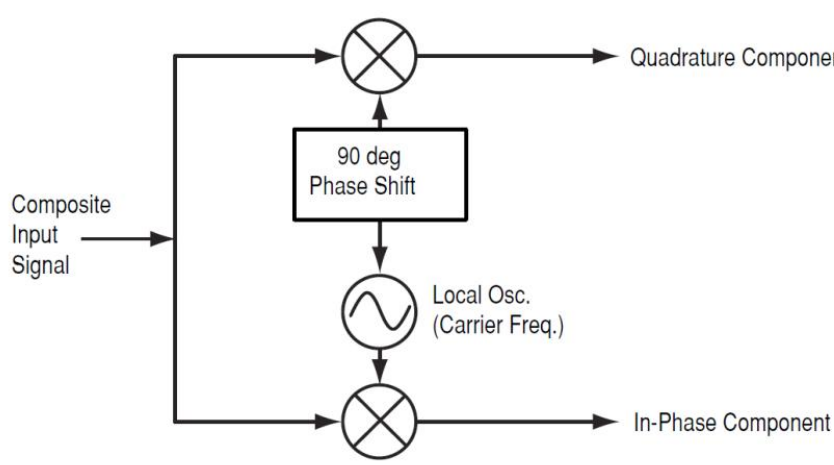

Figure 3.5 $I$ and $Q$ in a Practical Radio Receiver [2]

\section{$3.4 I$ and $Q$ in a radio receiver}

The composite signal with magnitude and phase (or $I$ and $Q$ ) information arrives at the receiver end. The input signal is mix with the local oscillator signal at the carrier frequency in two types. One is at an arbitrary zero phase. The other has a $90^{\circ}$ phase shift. The composite input signal (in terms of magnitude and phase) is thus broken into an in-phase and Quadrature component. These two mechanisms of the signal are self-governing and orthogonal. One can be changed without touching the other. Usually, information cannot be plotted in a polar format and reinterpreted as rectangular values without doing a polar-to-rectangular conversion. This conversion is exactly what is done by the in-phase and quadrature mixing processes in a digital radio. A phase shifter, local oscillator, and two mixers can perform the conversion accurately and efficiently.

\section{LITERATURE REVIEW}

Lots of researches being carried out in the in the wireless technologies among these the Wi-Max is the hottest trend of research in terms of enhancing the performance and quality of services. Few of the previous research on Wi-max is discussed here.

Askar, S.; Al-Raweshidy, H.S. [3] in 2011 worked on, "Performance evaluation of IEEE802.16-2004 Wi-MAX with fixed high fading channels,", Wi-MAX (Worldwide Interoperability for Microwave Access) is a promising technology which can offer high speed data, voice and video service to the customer end, which is presently, dominated by the cable and digital subscriber line (DSL) technologies. The performance assessment of Wi-MAX systems is dealt with. The biggest advantage of Broadband wireless application
(BWA) over its wired competitors is its increased capacity and ease of deployment. This work are to model and simulate the fixed OFDM IEEE 802.16d physical layer under variant combinations of digital modulation (BPSK, QPSK, and 16QAM) over diverse combination of fading channels (AWGN, SUIs).

Yong Su Lee; Young-Il Kim; Won Ryu; Lee Ho Jin; Tae-Sik Kim; Whan-Woo Kim,[4] in 2011 proposed "BER performance of pilot-aided channel estimation in mobile-WiMAX in the presence of frame synchronization errors,", they analyzed the available frame synchronization error ranges through the uncoded BER (bit error rate) performance in the condition of 64-QAM digital modulation in Mobile-Wi-MAX system.

Moraitis, N.; Vouyioukas, D.; Constantinou, Philip,[5] in 2011 done research on "Propagation Study and Performance Evaluation of a Mobile Wi-MAX System at $3.5 \mathrm{GHz}$,". This research is focused on a detailed coverage and performance analysis of wireless metropolitan area networks based on the IEEE 802.16 standard, which is the basis of Wi-MAX technology. A coverage study and performance evaluation of a mobile Wi-MAX system in an urban and suburban environment with the help of a software simulation tool is presented. All the required parameters are given to the program focusing only in suitable propagation models e.g. ITU-R 525/526, or COST231-HATA. The total coverage of the area was $67 \%$ from which $52 \%$ provides QAM modulation offering higher data rates to the users.

Iqbal, Z.; Nooshabadi, S.; Heung-No Lee,[6] in 2012 worked on "Analysis and design of coding and interleaving in a MIMO-OFDM communication system,". Use of Wireless Communication system for MAN in consumer electronics has increased significantly in the recent past. This work, presented the performance analysis of four different channel coding and interleaving schemes for MIMO-OFDM communications systems. A comparison is done based on the BER, hardware implementation resources requirement, and power dissipation. It also presented a memory-efficient and low-latency interleaver implementation technique for the MIMO-OFDM communication system. It is also the best technique as far as the hardware resource implication and power dissipation is concerned, which are particularly important in the context of consumer electronics. Next, using the proposed interleaver, a MIMO-OFDM based transmitter employing a double data stream $2 \times 2$ MIMO spatial multiplexing system is built.

Kahveci, S.,[7] in 2012, "Performances of Zigzag coding with high-level modulations on Wi-MAX system,". The Wi-MAX which is a technology of OFDM base provides wireless communication from one-point to multi-point. In this study, for fixed and mobile Wi-MAX systems performance analysis of different modulation types and Zigzag encoder schemes is investigated. One of the important advantages of the error correction codes has no need re-transmission of data packets. The results of proposed Zigzag-coded modulation show that they have a good performance at least other techniques.

Kamali, B.; Bennett, R.A.; Cox, D.C.,[9] in 2012, "Understanding Wi-MAX: An IEEE-802.16 Standard-Based Wireless Technology,". Worldwide Interoperability for Microwave Access (Wi-MAX) is an IEEE 802.16 based broadband Mobile wireless solution where orthogonal frequency division multiple access (OFDMA) is the method of sharing communication resources among large numbers of users. This is in contrast with multiple access technologies such as frequency division multiple access (FDMA), time 
division multiple access (TDMA), and code division multiple access (CDMA) that were dominant in $1 \mathrm{G}$ (first generation cellular systems), 2G, 2.5G, and $3 \mathrm{G}$ cellular networks. As the demand for wireless communications grows almost exponentially, the ability to access these networks becomes an important commodity.

Patidar, M.; Dubey, R.; Jain, N.K.; Kulpariya, S.,[10] in 2012, "Performance analysis of Wi-MAX 802.16e physical layer model,". This work discussed about the model building of the Wi-MAX physical layer using simulink in Matlab R2009a version. This model is a useful tool for BER (Bit Error Rate) performance evaluation for the real time audio data communication by the Wi-MAX physical layer, under different channel encoding rate, and digital modulation schemes and channel conditions, besides serving as a helpful resource for the students and the researchers who want to base their studies and research in the field of Wi-MAX. In this paper, transmitter and receiver model are simulated according to the parameters established by the standards, to evaluate the performance. Also convolution coding is used to improve the system performance. The performance analysis is being done by studying the bit loss and packet losses occurred during transmission over the channel.

Sekar, V.; Veerapagounder, P.; Baskaran, B.,[12] in 2012, "BER performance and frequency band efficiency analysis of fixed WI-MAX,". Worldwide Inter-operability for Microwave Access is an rising global broadband wireless system based on IEEE 802.16 standards. This paper investigated several modulation techniques for IEEE 802.16d (fixed WI-MAX) based OFDM system including BPSK, QPSK, 16QAM and 64QAM with different cyclic prefix are tested with channel frequency band of $1.75 \mathrm{MHz}$.

Sharef, Z.T.; Alaradi, A.E.; Sharef, B.T.,[13] in 2012, "Performance Evaluation for Wi-MAX 802.16e OFDMA Physical Layer,". In a detailed link level simulation has been studied and optimized to investigate the physical layer performance of Worldwide Interoperability for Microwave Access (Wi-MAX) IEEE 802.16e over AWGN and multipath
Rayleigh fading channels, in which ITU-Reference channel models have been used. Two 802.16e based OFDMA transceivers have been designed by using MATLAB Simulink, the first one doesn't support channel estimation whereas the second does. The bit error rate (BER) vs. bit energy-to-noise density ratio $(\mathrm{Eb} / \mathrm{No})$ curves was used to evaluate and compare the performance of QPSK modulation technique.

Paz Portela, N.A.; Rodriguez Diaz, B., in 2013 evaluated the "Performance Comparison between the Air Interfaces of LTE and Mobile Wi-MAX,". Shown that there is no doubt nowadays that Orthogonal Frequency Division Multiplexing (OFDM) is the dominant technology in the area of mobile wireless access. The objective of this work is to analyze and compare the performance and spectral efficiency of 3GPP Long Term Evolution (LTE) and mobile Worldwide Interoperability for Microwave Access (Wi-MAX). Both technologies (based in OFDM) are the dominant options to provide mobile broadband access today, and in the near future.

Prabakaran, N.; Shaji, K.S.,[16] in 2013 proposed a research on "Performance analysis of uplink MIMO in $2 \times 2$ mobile WiMAX system,", They analyzed the error rate performance (BER \& PER) of uplink coded $2 \times 2$ multiple-input multipleoutput orthogonal frequency division multiple access (MIMO OFDMA) systems under AWGN fading channel conditions. The IEEE 802.16 standard, commonly known as Wi-MAX, is the latest technology that has promised to offer broadband wireless access over long distance. Since $2001 \mathrm{Wi-MAX}$ has evolved from 802.16 to $802.16 \mathrm{~d}$ for fixed wireless access and to the new IEEE 802.16e standard with mobility support. In Wi-MAX, multiple input multiple-output (MIMO) antenna technologies play an essential role in meeting the $4 \mathrm{G}$ requirements. The application of MIMO technologies is one of the most crucial distinctions between $3 \mathrm{G}$ and $4 \mathrm{G}$. A large family of MIMO techniques has been developed for various links and with various amounts of available channel state information in IEEE $802.16 \mathrm{e} / \mathrm{m}$.

Table 1: Summary of Literature Review

\begin{tabular}{|c|c|c|c|c|}
\hline Year & Author & Title & Apprach & Result \\
\hline 2011 & $\begin{array}{l}\text { Askar, S.; Al- } \\
\text { Raweshidy, H.S. }\end{array}$ & $\begin{array}{l}\text { Performance evaluation of IEEE802.16- } \\
2004 \text { Wi-MAX with fixed high fading } \\
\text { channels }\end{array}$ & $\begin{array}{l}\text { Variant combinations of digital } \\
\text { modulation (BPSK, QPSK, and } \\
\text { 16-QAM) over diverse } \\
\text { combination of fading channels } \\
\text { (AWGN, SUIs) }\end{array}$ & $\begin{array}{c}\text { Increased capacity and ease } \\
\text { of deployment }\end{array}$ \\
\hline 2011 & $\begin{array}{c}\text { Yong Su Lee; } \\
\text { Young-Il Kim; Won } \\
\text { Ryu; Lee Ho Jin; } \\
\text { Tae-Sik Kim; Whan- } \\
\text { Woo Kim } \\
\end{array}$ & $\begin{array}{c}\text { BER performance of pilot-aided channel } \\
\text { estimation in mobile-Wi-MAX in the } \\
\text { presence of frame synchronization } \\
\text { errors }\end{array}$ & 64-QAM digital modulation & $\begin{array}{c}\text { Synchronization error } \\
\text { ranges through the uncoded } \\
\text { BER }\end{array}$ \\
\hline 2011 & $\begin{array}{c}\text { Moraitis, N.; } \\
\text { Vouyioukas, D.; } \\
\text { Constantinou, Philip }\end{array}$ & $\begin{array}{c}\text { Propagation Study and Performance } \\
\text { Evaluation of a Mobile Wi-MAX } \\
\text { System at } 3.5 \mathrm{GHz} \\
\end{array}$ & QAM modulation & $\begin{array}{l}\text { Offering higher data rates } \\
\text { to the users }\end{array}$ \\
\hline 2012 & $\begin{array}{c}\text { Iqbal, Z.; } \\
\text { Nooshabadi, S.; } \\
\text { Heung-No Lee } \\
\end{array}$ & $\begin{array}{l}\text { Analysis and design of coding and } \\
\text { interleaving in a MIMO-OFDM } \\
\text { communication system }\end{array}$ & $\begin{array}{l}\text { Memory-efficient and low- } \\
\text { latency interleaver } \\
\text { implementation technique }\end{array}$ & $\begin{array}{l}\text { Double data stream } 2 \times 2 \\
\text { MIMO spatial multiplexing } \\
\text { system }\end{array}$ \\
\hline 2012 & Kahveci, S. & $\begin{array}{l}\text { Performances of Zigzag coding with } \\
\text { high-level modulations on Wi-MAX } \\
\text { system }\end{array}$ & $\begin{array}{l}\text { Zigzag-coded High-level } \\
\text { modulations }\end{array}$ & $\begin{array}{c}\text { Good performance at least } \\
\text { other techniques }\end{array}$ \\
\hline
\end{tabular}




\begin{tabular}{|c|c|c|c|c|}
\hline 2012 & $\begin{array}{c}\text { Kamali, B.; Bennett, } \\
\text { R.A.; Cox, D.C }\end{array}$ & $\begin{array}{c}\text { Understanding Wi-MAX: An IEEE- } \\
802.16 \text { Standard-Based Wireless } \\
\text { Technology }\end{array}$ & $\begin{array}{c}\text { Frequency division multiple } \\
\text { access (FDMA), time division } \\
\text { multiple access (TDMA), and } \\
\text { code division multiple access } \\
\text { (CDMA) }\end{array}$ & Grows almost exponentially \\
\hline 2013 & $\begin{array}{c}\text { Prabakaran, N.; } \\
\text { Shaji, K.S. }\end{array}$ & $\begin{array}{c}\text { Performance analysis of uplink MIMO } \\
\text { in } 2 \times 2 \text { mobile Wi-MAX system }\end{array}$ & $\begin{array}{c}\text { MIMO technique has been } \\
\text { developed for various links } \\
\text { and with various amounts } \\
\text { of available channel }\end{array}$ \\
\hline
\end{tabular}

\section{CONCLUSIONS AND FUTURE SCOPE}

To improve the performance of the present 802.16 standards, we studied major areas for future innovation and enhancement. The Wi-MAX technology continues to evolve with the Wi-MAX Forum's approval of the Release-1 mobile Wi-MAX system performance profiles based on the 802.16e 2005 modification. With OFDMA, mobile Wi-MAX can meet the severe requirements necessary for the delivery of broadband services in a challenging mobile surroundings. Simulations show that mobile Wi-MAX provides greater throughput and spectral effectiveness compared to planned 3G CDMA-based technologies, HSPA \& EVDO. These advantages will provide operators with added network capacity for the support of value-added services with fewer base stations than alternative approaches thus resulting in lower network capital and operating costs. When signal to noise ratio (SNR) exceed results in the Error Rate being lower than the BER threshold. Under the worst channel conditions in this system a fixed modulation technique is used and the sub carrier modulation designed to provide an acceptable BER. This results in the majority systems using QPSK or BPSK. These modulation techniques also give better spectral efficiency.

A lot of work can be done for future optimization of Wireless communication particularly in Wi-MAX system. Adaptive modulation techniques and Wi-MAX physical layer can be adopted with High Amplitude Platform (HAP) and Long Term Evaluation (LTE). As we used SUI-3 channel model along with AWGN, Rayleigh and Rician Fading channels, performance of Mobile Wi-MAX can be evaluated in other types of channel model.

\section{REFERENCES}

[1]. http://www.wimaxforum.org/resources/technicalspecifications

[2]. Agilent, "Digital Modulation in Communications Systems —An Introduction", Application Note 1298.

[3]. Askar, S.; Al-Raweshidy, H.S., "Performance evaluation of IEEE802.16-2004 Wi-MAX with fixed high fading channels," Wireless and Microwave Technology Conference (WAMICON), 2011 IEEE 12th Annual, vol., no., pp.1,6, 18-19 April 2011.

[4]. Yong Su Lee; Young-Il Kim; Won Ryu; Lee Ho Jin; TaeSik Kim; Whan-Woo Kim, "BER performance of pilotaided channel estimation in mobile-Wi-MAX in the presence of frame synchronization errors," ICT Convergence (ICTC), 2011 International Conference on, vol., no., pp.485,486, 28-30 Sept. 2011.

[5]. Moraitis, N.; Vouyioukas, D.; Constantinou, Philip, "Propagation Study and Performance Evaluation of a Mobile Wi-MAX System at $3.5 \mathrm{GHz}$, Communications (ICC), 2011 IEEE International Conference on, vol., no., pp.1,5, 5-9 June 2011.
[6]. Iqbal, Z.; Nooshabadi, S.; Heung-No Lee, "Analysis and design of coding and interleaving in a MIMO-OFDM communication system," Consumer Electronics, IEEE Transactions on, vol.58, no.3, pp.758,766, August 2012.

[7]. Kahveci, S., "Performances of Zigzag coding with highlevel modulations on Wi-MAX system," Signal Processing and Communications Applications Conference (SIU), 2012 20th, vol., no., pp.1,4, 18-20 April 2012.

[8]. Yuan-Cheng Lai; Yen-Hung Chen; Ching-Neng Lai, "A Channel Quality Aware Algorithm for IEEE 802.16 Uplink Burst Construction," Advanced Information Networking and Applications (AINA), 2012 IEEE 26th International Conference on , vol., no., pp.207,214, 26-29 March 2012.

[9]. Kamali, B.; Bennett, R.A.; Cox, D.C., "Understanding WiMAX: An IEEE-802.16 Standard-Based Wireless Technology," Potentials, IEEE, vol.31, no.5, pp.23,27, Oct. 2012.

[10]. Patidar, M.; Dubey, R.; Jain, N.K.; Kulpariya, S., "Performance analysis of Wi-MAX 802.16e physical layer model," Wireless and Optical Communications Networks (WOCN), 2012 Ninth International Conference on, vol., no., pp.1,4, 20-22 Sept. 2012.

[11]. Dutta, N.; Biradar, S.R., "Interoperability of WiFi and WiMAX," Parallel Distributed and Grid Computing (PDGC), 2012 2nd IEEE International Conference on, vol., no., pp.747,751, 6-8 Dec. 2012.

[12]. Sekar, V.; Veerapagounder, P.; Baskaran, B., "BER performance and frequency band efficiency analysis of fixed WI-MAX," Computing Communication \& Networking Technologies (ICCCNT), 2012 Third International Conference on, vol., no., pp.1,4, 26-28 July 2012.

[13]. Sharef, Z.T.; Alaradi, A.E.; Sharef, B.T., "Performance Evaluation for Wi-MAX 802.16e OFDMA Physical Layer," Computational Intelligence, Communication Systems and Networks (CICSyN), 2012 Fourth International Conference on, vol., no., pp.351,355, 24-26 July 2012.

[14]. Paz Portela, N.A.; Rodriguez Diaz, B., "Performance Comparison between the Air Interfaces of LTE and Mobile Wi-MAX," Latin America Transactions, IEEE (Revista IEEE America Latina), vol.11, no.4, pp.1001,1006, June 2013.

[15]. Kharthika, B.; Vigneswari, G.M., "Performance resolution of cross-layer framework in Wi-MAX OFDMA," Information Communication and Embedded Systems (ICICES), 2013 International Conference on , vol., no., pp.773,779, 21-22 Feb. 2013. 
[16]. Prabakaran, N.; Shaji, K.S., "Performance analysis of uplink MIMO in $2 \times 2$ mobile Wi-MAX system," Signal Processing Image Processing \& Pattern Recognition (ICSIPR), 2013 International Conference on, vol., no., pp.6,9, 7-8 Feb. 2013.

\section{AUTHOR'S PROFILE}

Smriti Shrivastava is a research scholar at Sagar Institute of Science and Technology, Bhopal, M.P., INDIA. She is pursuing her M.Tech. in Digital Communication. Her research interests are wireless technologies and improvements in the modern digital communication.

Prof. Md. Abdullah is working research scholar at Sagar Institute of Science and Technology, Bhopal, M.P., INDIA. She is pursuing her M.Tech. in Digital Communication. Her research interests are wireless technologies and improvements in the modern digital communication. 